\title{
Cervical spondylarthrotic myelopathy with early onset in Down's syndrome: five cases and a review of the literature
}

\author{
G. P. Th. Bosma, ${ }^{1,2}$ M. A. van Buchem, ${ }^{2}$ J. H. C. Voormolen, ${ }^{3}$ F. C. van Biezen ${ }^{4} \&$ \\ O. F. Brouwer'
}

I Department of Neurology, Leiden University Medical Centre, Leiden, the Netherlands

2 Department of Radiology, Leiden University Medical Centre, Leiden, the Netherlands

3 Department of Neurosurgery, Leiden University Medical Centre, Leiden, the Netherlands

4 Department of Orthopaedic Surgery, Academic Hospital Dijkzigt, Rotterdam, the Netherlands

\begin{abstract}
Progressive walking difficulties and bladder dysfunction may be attributed to Alzheimer disease or atlanto-axial subluxation in people with Down's syndrome (DS). The present authors describe five patients with DS suffering from the above symptoms as a result of cervical spondylarthrotic myelopathy. Clinical and radiological data were collected from all patients with DS who underwent surgery for cervical spondylarthrotic myelopathy at the Leiden University Medical Centre during the period between 199I and 1995. Five patients with DS (four males and one female) were identified. Their mean age at diagnosis was 42 years. The main clinical features were weakness of the arms and legs, ataxic gait, hyperreflexia and bilateral Babinski signs. Radiological examination showed spondylarthrosis, compression of the spinal cord and myelomalacia. The mean delay in diagnosis was 3 years. All five individuals showed clinical stabilization after laminectomy. Cervical spondylarthrotic myelopathy seems a rather frequent

Correspondence: O. F. Brouwer MD, Department of Neurology, Leiden University Medical Centre, P.O. Box 9600, 2300 RC Leiden, the Netherlands.

disorder in DS, occurring at a relatively young age. Early diagnosis may prevent irreversible neurological deficits.

Keywords cervical vertebrae, Down's syndrome, spinal canal, spinal cord compression

\section{Introduction}

Down syndrome (DS) is frequently associated with cervical spine abnormalities. Most physicians are familiar with atlanto-axial instability caused by traumatic rupture or non-traumatic ligamentous laxity of the ligamentum transversum, which may lead to upper cervical spinal cord injury. The reported prevalence of atlanto-axial instability, defined as an anterior atlanto-odontoid distance of $\geqslant 3 \mathrm{~mm}$, ranges between $8 \%$ and $40 \%$ (Alvarez \& Rubin 1986; Maclachlan et al. 1993). Recently, other disorders causing cervical myelopathy in patients with DS have been described, such as odontoid abnormalities, atlanto-occipital abnormalities and hypoplasia of the posterior arch of $\mathrm{C}_{1}$ (Martich et al. I992). Less well known are the degenerative abnormalities of the middle and lower cervical spine 
G. P. Th. Bosma et al • Cervical spondylarthrotic myelopathy in Down's syndrome

which can be frequently found in relatively young adults with DS and may cause a progressive myelopathy (Olive et al. I988). Moderate or severe degenerative disease of the cervical spine was found in 45 members of a population of 99 institutionalized adults with DS who had a mean age of $35 \pm 9$ years, the most commonly affected level being $\mathrm{C}_{5}-\mathrm{C}_{6}$ (Maclachlan et al. I993). The attention of physicians in patients with DS with walking difficulties and bladder dysfunction may be mainly focused on brain disorders or atlanto-axial subluxation. Therefore, the diagnosis of cervical spondylarthrotic myelopathy may be inappropriately delayed. The present authors describe the clinical and radiological findings in five patients with DS who underwent neurosurgical intervention because of this disorder.

\section{Subjects and methods}

All patients with DS with cervical spondylarthrotic myelopathy who underwent surgery in the period between I99I and I995 at the Department of Neurosurgery, Leiden University Medical Centre, Leiden, the Netherlands, which provides neurosurgical care for approximately one million people, were included in the present study. Based on an epidemiological study of patients with DS in the Netherlands (Steffelaar \& Evenhuis 1989), the number of DS individuals in this region of neurosurgical care is estimated to be over 500 individuals with DS. Clinical data were collected from the patient files. All available conventional cervical spine radiographs, myelographies, and computed tomography and magnetic resonance imaging (MRI) scans were reviewed by the second author (M.A.B.).

\section{Results}

In the period between I99I and I995, five patients with DS (four males and one female) were diagnosed with cervical spondylarthrotic myelopathy and treated in the present authors' medical centre. The main clinical and radiological features of the subjects are listed in Table $\mathrm{I}$. Their mean age at the time of diagnosis was 42 years (range $=27^{-}$ 52 years); their mean age at the onset of symptoms was 39 years (range $=25-50$ years). The subjects all presented with progressive walking difficulties caused by combined weakness and ataxia of the lower limbs. In addition, they all showed hyperreflexia and bilateral Babinski signs at neurological examination. Two subjects had symptoms of bladder dysfunction. Cervical spine radiographs were performed with additional cervical myelography or MRI in all five individuals. In all five patients, no evidence was found for occipital- $\mathrm{C}_{1}$ abnormalities, atlanto-axial subluxation, dens disorders or hypoplastic arches. In the three patients who underwent MRI, myelomalacia was detected on the same level of compression and spondylarthrosis. The remaining two patients also showed compression and spondylarthrosis. After the diagnosis of cervical myelopathy, all the subjects underwent laminectomy. The clinical situation of all five patients did not improve despite this procedure. Two illustrative cases are presented.

\section{Case I (patient 2)}

This male patient with DS was first neurologically examined at the age of 32 years because of deterioration of cognitive performance, intermittently abnormal gait and episodes of dizziness. Neurological examination revealed no clear abnormalities. An electroencephalogram at that time was normal. He was then referred to an ophthalmologist who found decreased visual acuity as a result of bilateral cataract. However, neither his mental nor motor performance improved after a lens extraction of the left eye. Because of further deteriorating gait and frequent falling, the neurological examination was repeated 2 years later, and showed mild spastic paraparesis (MRC grade IV) with hyperreflexia and bilateral Babinski signs. Computed tomography of the brain showed no abnormalities. A radiograph of the cervical spine showed marked disc narrowing at all cervical levels, with a posterior osteophyte at $\mathrm{C}_{3}-\mathrm{C}_{4}$, but no signs of atlanto-axial instability (Fig. 1a). The subject's walking difficulties had progressively increased and he frequently had to use a wheelchair only 3 years later, when the subject was 37 years old. At that time, the motor function of his arms was still normal, but he had a spastic-ataxic gait with generalized hyperreflexia and bilateral Babinski 
G. P. Th. Bosma et al • Cervical spondylarthrotic myelopathy in Down's syndrome

Table I Clinical and radiological data of five patients with Down's syndrome and cervical myelopathy*

\begin{tabular}{|c|c|c|c|c|c|}
\hline \multirow[b]{2}{*}{ Characteristic } & \multicolumn{5}{|c|}{ Patient number (sex) } \\
\hline & I (M) & $2(M)$ & $3(M)$ & $4(M)$ & $5(F)$ \\
\hline Age at onset (years) & 43 & 31 & 25 & 44 & 50 \\
\hline Age at diagnosis (years) & 45 & 37 & 27 & 47 & 52 \\
\hline \multicolumn{6}{|l|}{ Main clinical features: } \\
\hline weakness of arms/hands & + & - & + & - & + \\
\hline weakness of legs & + & + & + & + & + \\
\hline ataxic gait & + & + & + & + & $?$ \\
\hline bladder dysfunction & - & - & $+?$ & + & - \\
\hline hyperreflexia & + & + & + & + & + \\
\hline Babinski sign & + & + & + & + & + \\
\hline \multicolumn{6}{|l|}{ Radiological examination: } \\
\hline X-cervical spine & + & + & + & + & + \\
\hline myelography & + & ND & + & ND & ND \\
\hline computed tomography & ND & + & + & ND & ND \\
\hline magnetic resonance imaging & ND & + & ND & + & + \\
\hline \multicolumn{6}{|l|}{ Main radiological findings: } \\
\hline main level(s) of spondylosis & $\mathrm{C}_{2}-\mathrm{Thl}$ & $\mathrm{C}_{3}-\mathrm{C}_{4}$ & $\mathrm{C}_{3}-\mathrm{C}_{4}$ & $\mathrm{C}_{3}-\mathrm{ThI}$ & $\mathrm{C}_{2}-\mathrm{C}_{5}$ \\
\hline main level(s) of compression & $\mathrm{C}_{4}-\mathrm{C}_{5}$ & $\mathrm{C}_{2}-\mathrm{C}_{3}$ & $\mathrm{C}_{3}-\mathrm{C}_{4}$ & $\mathrm{C}_{3}-\mathrm{C}_{4}$ & $\mathrm{C}_{3-4} / \mathrm{C}_{4-5}$ \\
\hline \multicolumn{6}{|l|}{ Neurosurgical intervention: } \\
\hline level of dorsal laminectomy & $\frac{1}{2} C_{2}-C_{6}$ & $\mathrm{C}_{2}-\mathrm{C}_{5}$ & $\frac{1}{2} C_{3}-C_{6}$ & $\frac{1}{2} C_{2}-\frac{1}{2} C_{7}$ & $\frac{1}{2} C_{2}-C_{6}$ \\
\hline Postoperative & Stable & Stable & Stable & Deterioration & Deterioration \\
\hline
\end{tabular}

*Key: (+) positive; (-) negative; and (ND) not done.

signs. An MRI scan revealed a marked compression of the spinal cord and signs of myelomalacia at level $\mathrm{C}_{2}-\mathrm{C}_{3}$ which could explain the pyramidal syndrome (Fig. Ib). The diagnosis was set on cervical myelopathy and a laminectomy from $\mathrm{C}_{2}$ to $\mathrm{C}_{5}$ was performed. During the 3 years since, the subject's neurological condition has not changed.

\section{Case 2 (patient 4)}

This male patient with DS presented at the age of 47 years with a progressively deteriorating gait with a weakness of both legs during the past 6 months. He was also found to have had a bladder dysfunction with overflow incontinence for 3 years. Neurological examination revealed no overt abnormalities of the arms, but elevated tendon reflexes of the lower extremities and bilateral Babinski signs. An MRI of the cervical spine showed degenerated, bulging discs at levels $\mathrm{C}_{3}-\mathrm{C}_{4}$ down to $\mathrm{C}_{6}-\mathrm{C}_{7}$, and posterior spondylophytes at $\mathrm{C}_{3}-\mathrm{Th}_{1}$. Compression of the spinal cord and overt myelomalacia could be observed at the $\mathrm{C}_{3}-\mathrm{C}_{4}$ level. Again, there were no signs of atlanto-axial instability (Fig. 2a). The subject was diagnosed as having cervical myelopathy and neurosurgical intervention was indicated. A preoperatively made lateral radiograph of the cervical spine showed disc space narrowing at all cervical levels, osteophytic formation and sclerosis of vertebral bodies $\mathrm{C}_{5}-\mathrm{C}_{6}$ (Fig. 2b). A laminectomy from $\mathrm{C}_{2}$ to $\mathrm{C}_{7}$ was performed. Despite this intervention, the subject's neurological condition further deteriorated.

\section{Discussion}

Cervical spondylarthrotic myelopathy is a serious and irreversible disorder which needs early detection and treatment. A full-blown cervical myelopathy can be highly disabling with progressive neurological dysfunction. In individuals with DS, a correct diagnosis of a (lower) cervical spondylarthrotic myelopathy is often delayed, as was the case in the patients in the present study. The main reasons for such a delay are that doctors relate the signs and symptoms of myelopathy to progressive cerebral 

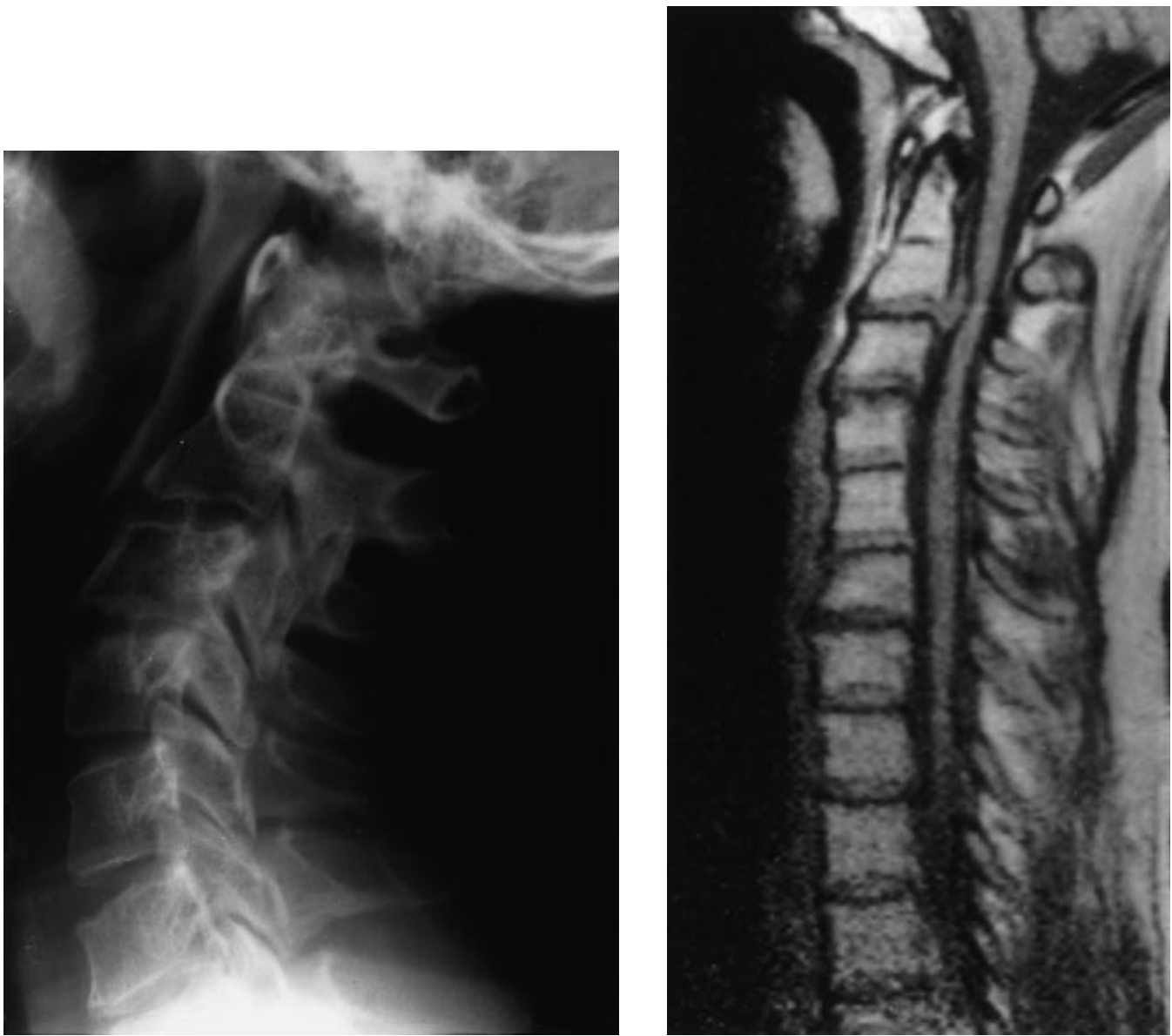

Figure I Case 1: (a) A lateral radiograph of the cervical spine showing disc space narrowing which is suggestive of degenerated intervertebral discs. There is a posterior osteophyte at the $\mathrm{C}_{3-4}$ level. (b) A magnetic resonance image of the cervical spine ( $\mathrm{T}_{1}$-weighted sagittal image). There are narrow intervertebral discs at all levels, and a herniated disc at the $\mathrm{C}_{2-3}$ level with compression of the spinal cord.

dysfunction, and that they are not familiar with this kind of pathology in patients with DS. The mean delay in diagnosis in the five patients in the present study was 3 years. If cervical myelopathy is diagnosed too late, neurosurgical intervention often can not prevent further deterioration (Murali \& Masdeu 1997). The diagnostic delay in the present sample may explain the poor results after neurosurgical intervention.

In individuals with Down's syndrome, cervical myelopathy is often associated with atlanto-axial subluxation, but it is less known that other levels of the cervical spine can show marked degenerative changes at relatively young age (Tangerud et al. I990). Degenerative disease of the cervical spine, which consists of disc space narrowing, osteophytic formation, deformity, or subluxation and sclerosis can lead to myelopathy (Pallis et al. I954; Nurick I972). Maclachlan et al. (I993) found that the levels of the cervical spine affected ranged from $\mathrm{C}_{2}$ to $\mathrm{C}_{6}$ in patients with DS and that the most commonly affected level was $\mathrm{C}_{5}-\mathrm{C}_{6}$. Degenerative changes were found more frequently, and if present, were more severe in patients with DS than in controls. This may lead to the conclusion that individuals with DS are also at higher risk of developing cervical myelopathy, especially at lower cervical levels.

Down's syndrome is characterized by accelerated ageing (Martin 1982), and as a consequence, disorders typical of old age may occur in relatively young patients with DS. Arthrosis is one of these disorders. Fidone (I986) reported that, out of $4 \mathrm{I}$

(C) 1999 Blackwell Science Ltd, Fournal of Intellectual Disability Research 43, 283-288 

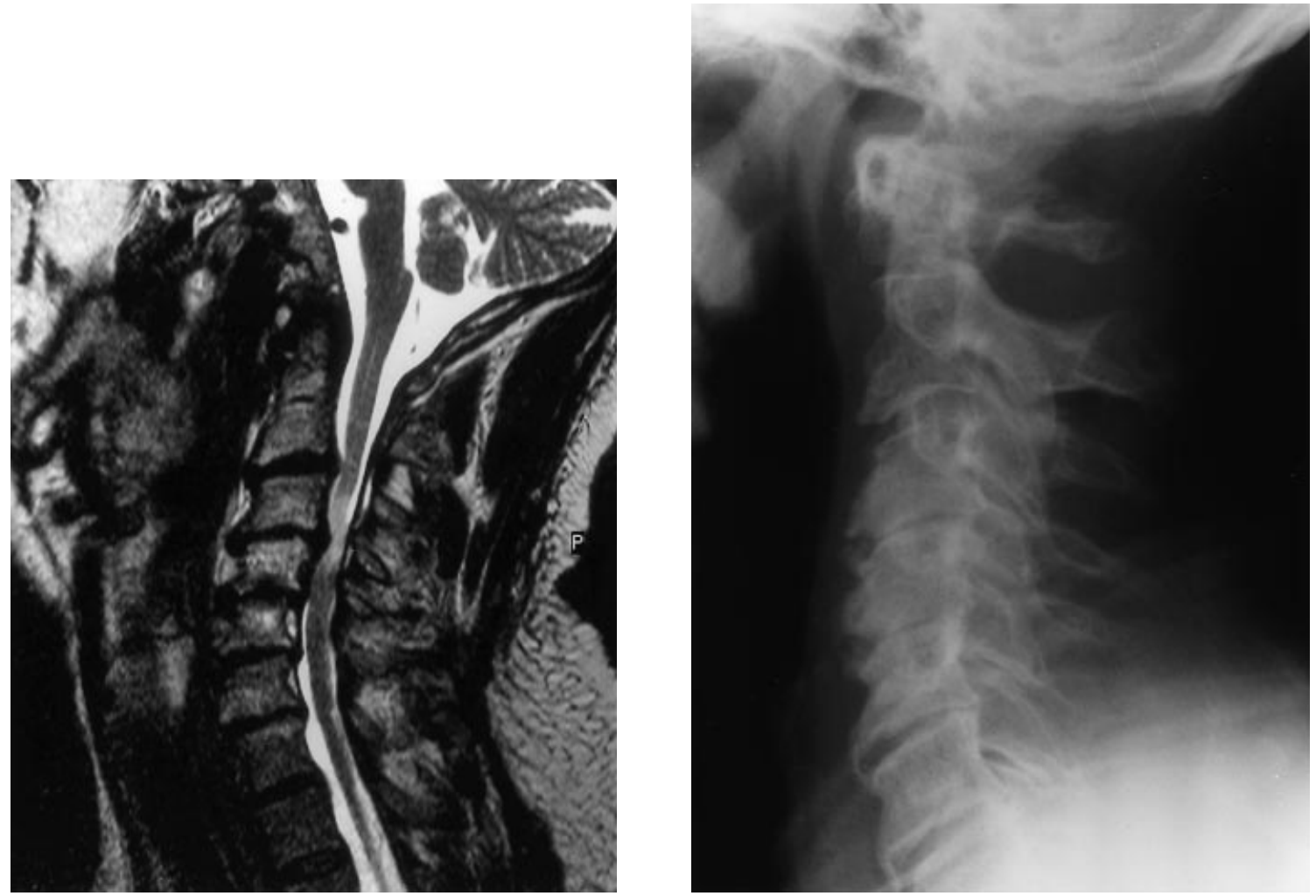

Figure 2 Case 2: (a) A magnetic resonance image of the cervical spine ( $\mathrm{T}_{2}$-weighted sagittal image). The narrowed spinal canal has been caused by degenerative disease. There is compression of the spinal cord at the $\mathrm{C}_{3-4}$ level with a high signal intensity which is indicative of myelomalacia. (b) A lateral radiograph of the cervical spine showing disc space narrowing at all cervical levels, and both anterior and posterior osteophytes. Note the sclerosis of vertebral bodies $\mathrm{C}_{5-6}$.

adult institutionalized patients with DS, 50\% of those between 30 and 40 years, and up to $100 \%$ of those over the age of 40 had signs of arthrotic degeneration of the cervical vertebrae, which was characterized by osteophytes, subarticular sclerosis, cystic changes or disc space narrowing. This finding suggests an early development of arthrosis in DS. Furthermore, DS is also characterized by patellar subluxation, dislocation of the hip, pes planus and atlanto-axial subluxation, indicating a tendency for ligamentous laxity (Diamond et al. I98I). The ligamentous laxity of the cervical segments may give rise to increased motility of these segments, subsequently causing the development of degenerative disease, like spondylosis and arthrosis. This may lead to secondary narrowing of the cervical canal, and thus, to cervical myelopathy. This same sequence has been described for patients without DS, but in these cases, it tends to be present almost universally above the age of 65 years and is often superposed on a pre-existent congenital narrow canal. The width of the cervical canal in DS individuals has not been systematically studied. A hypoplastic posterior arch of $\mathrm{C}_{1}$ has been described in ten out of 38 children with DS, but no hypoplasia of lower levels of the cervical spine was found (Martich et al. 1992). Therefore, there are no indications that individuals with DS are prone to a developmentally narrow cervical canal.

In case of a clinical suspicion of cervical myelopathy, an MRI scan of the cervical spine may confirm the diagnosis (McAfee et al. I986). In patients with DS presenting with ataxia, progressive gait disorder, weakness of arms or legs, or bladder dysfunction, one should consider lower cervical spondylarthrotic myelopathy in the differential diagnosis since this is an underestimated disorder with serious consequences. The irreversibility of this

(C) 1999 Blackwell Science Ltd, fournal of Intellectual Disability Research 43, 283-288 


\section{G. P. Th. Bosma et al • Cervical spondylarthrotic myelopathy in Down's syndrome}

disorder makes early detection and even prevention highly preferable.

\section{Acknowledgements}

The authors wish to thank Dr H. M. Evenhuis for critically reviewing this manuscript.

\section{References}

Alvarez N. \& Rubin L. (1986) Atlanto-axial instability in adults with Down's syndrome: a clinical and radiological survey. Applied Research in Mental Retardation 7, 67-78.

Diamond L. S., Lynne D. \& Sigman B. (I98I) Orthopaedic disorders in patients with Down's syndrome. Orthopedic Clinics of North America 12, 57-71.

Fidone G. S. (1986) Degenerative cervical arthritis and Down's syndrome. New England fournal of Medicine 314, 320.

Maclachlan R. A., Fidler K. E., Yeh H., Hodgetts P. G., Pharand G. \& Chau M. (1993) Cervical spine abnormalities in institutionalized adults with Down's syndrome. Fournal of Intellectual Disability Research 37, 277-85.

Martich V., Ben-Ami T., Yousefzadeh D. K. \& Roizen N. J. (I992) Hypoplastic posterior arch of C-1 children with Down syndrome: a double jeopardy. Radiology 183, I25-8.
Martin G. M. (1982) Syndromes of accelerated aging. National Cancer Institute Monographs 6o, 24I-7.

McAfee P. C., Bohlman H. H., Han J. S. \& Salvagno R. T. (1986) Comparison of nuclear magnetic resonance imaging and computed tomography in the diagnosis of upper cervical spinal cord compression. Spine II, 295304.

Murali R. \& Masdeu J. C. (1997) Cervical spondylotic myelopathy. In: Gait Disorders of Aging: Falls and Therapeutic Strategies (eds Masdeu J. C., Sudarsky L. \& Wolfson L.), pp. 197-208. Lippincott-Raven, Philadelphia, PA.

Nurick S. (1972) The pathogenesis of the spinal cord disorder associated with cervical spondylosis. Brain 95, 87-100.

Olive P. M., Whitecloud T. S., III \& Bennett J. T. (I988) Lower cervical spondylosis and myelopathy in adults with Down's syndrome. Spine 7, 78I-4.

Pallis C., Jones A. M. \& Spillane J. D. (I954) Cervical spondylosis. Brain 77, 274-89.

Steffelaar J. W. \& Evenhuis H. M. (1989) Epidemiologisch onderzoek naar de te verwachten aantallen oudere patiënten met het syndroom van Down in de jaren 19902025. Nederlands Tijdschrift voor Geneeskunde 22, II2 I-5.

Tangerud A., Hestnes A., Sand T. \& Sunndalsfoll S. (I990) Degenerative changes in the cervical spine in Down's syndrome. Fournal of Mental Deficiency Research 34, I79-85.

Received 20 October 1998; revised 25 February 1999 